\title{
Genetic Analysis of Chicken Lines by Amplified Fragment Length Polymorphism (AFLP)
}

\author{
Eun Jun LEE, Hideyuki MANNEN ${ }^{1}$, Makoto MIZUTANI ${ }^{2}$ and Soichi TSUJI ${ }^{1}$ \\ Graduate School of Science and Technology, Kobe University, Nada-ku, \\ Kobe-shi 657-8501, Japan \\ ${ }^{1}$ Faculty of Agriculture, Kobe University, Nada-ku, \\ Kobe-shi 657-8501, Japan \\ ${ }^{2}$ Nippon Institute of Biological Science, Kobuchizawa-machi, \\ Yamanashi-ken 408-0041, Japan
}

(Received December 8, 1999 ; Accepted March 17, 2000)

\begin{abstract}
The amplified fragment length polymorphism (AFLP) was applied to analyze genetic variation and relationships of eight chicken lines including Black Minorca (BM-C), White Leghorn (WL-GM) and Fayoumi (PNP, PNP/DO, PNN, GSN/1, GSN/2, and GSP) lines. Genomic DNA digested with $E c o \mathrm{R} \mathrm{I}$ and $M s e \mathrm{I}$ was ligated to $E c o \mathrm{R} \mathrm{I}$ and $M s e \mathrm{I}$ adapters and the fragments were amplified using four primer sets, each having three selective nucleotides at the $3^{\prime}$ end. A fluorescent labeled Eco RI primer was used for the second amplification. A total of 188 distinctive bands were obtained with combinations of the four primer sets, of which 82 bands were polymorphic through the lines. The number of polymorphic bands between two lines were quite variable from 3 to 28 . The average genetic variation expressed as band sharing (BS) values, ranged from 0.91 to 0.97 within chicken lines, while those values between breeds ranged from 0.37 to 0.51 . A dendrogram constructed using the unweighted pair group method average (UPGMA) showed that these chicken lines could be classified into three breed-dependent groups and six Fayoumi lines were classified further into two sub-groups. The fingerprinting of DNA by AFLP offers a powerful and convenient tool not only for assessment of inbreeding, but also for revealing genetic relationships between chicken lines prior to the construction of a resource family for linkage analysis.
\end{abstract}

Animal Science Journal 71 (3) : 231-238, 2000

Key words : AFLP fingerprint, Chicken lines, Genetic variation, Genetic relationships

The DNA fingerprinting technique called amplified fragment length polymorphism (AFLP) was developed by Vos et al. ${ }^{12}$. AFLP generates subsets of polymorphic restriction fragments using selective primer sets corresponding to ligated adapters. AFLP fingerprinting is cost-effective and can detect unlimited numbers of loci though the use of selective primers and different restriction enzyme combinations ${ }^{6}$.

Initially, the AFLP method was applied to plants, because the construction of resource familes for linkage analysis in plants is easier than in animals. As the efficiency and reliability of the method became widely, examples of its application to animals began to appear, e.g., for cattle ${ }^{1\rangle}$, rat $^{10)}$ and chicken ${ }^{3.6)}$.

We have established 16 chicken lines with unique genetic characteristics derived from Black Minorca, White leghorn and Fayoumi at the Nippon Institute of Biological Science (NIBS). Although these lines are non-inbred (Table 1), they have been maintained for more than 20 years as a closed colony with few breeding chickens, and as a result have fixed genetic characteristics and interesting immune traits. Therefore, they represent a unique genetic resource for the study of phenotype and genotype in chickens. Prior

Corresponding : Soichi TSUJI (fax : +81 (0) 78-803-5801, e-mail : tsuji@ans.kobe-u.ac.jp)

Anim. Sci. J. 71 (3) : 231-238, 2000 
LEE, MANNEN, MIZUTANI and TSUJI

Table 1. Description of chicken lines established by Nippon Institute of Biological Science (NIBS)

\begin{tabular}{|c|c|c|c|c|c|c|c|}
\hline \multirow[b]{2}{*}{ Breed } & \multirow[b]{2}{*}{ Line } & \multirow{2}{*}{$\begin{array}{l}\text { Years } \\
\text { and } \\
\text { Generations }\end{array}$} & \multirow{2}{*}{$\begin{array}{c}\text { Initial } \\
\text { population }\end{array}$} & \multicolumn{3}{|c|}{ Fixed allele } & \multirow{2}{*}{$\begin{array}{l}\text { Other genetic } \\
\text { characteristics }\end{array}$} \\
\hline & & & & $\begin{array}{l}\text { Blood } \\
\text { groups }\end{array}$ & $\begin{array}{l}\text { Blood protein and } \\
\text { serum isozyme types }\end{array}$ & Other loci** & \\
\hline $\begin{array}{l}\text { Black- } \\
\text { Minorca }\end{array}$ & BM-C & $20^{\mathrm{b}}\left(76^{\mathrm{c}}\right)$ & $\begin{array}{l}\text { one male } \\
\text { /two female }\end{array}$ & $\begin{array}{l}A 2, B 15 \\
C 4, D 2 \\
H 2, I 3 \\
P 4\end{array}$ & $\begin{array}{l}H b-I^{A}, H b-I I^{A} \\
H b-I I I^{A}, C t^{B}, E s-I^{S} \\
E s-2^{A}, A k p^{S}, L a p^{A}\end{array}$ & $\begin{array}{l}\mathrm{OTC}^{\mathrm{S}} \\
\mathrm{MHC}^{B-G, B-F}\end{array}$ & $\begin{array}{l}\text { High sensitivity to fowl pox } \\
\text { High resistance to Marek's, } \\
\text { low response to Mycoplasma } \\
\text { gallisaepticum }\end{array}$ \\
\hline $\begin{array}{l}\text { White- } \\
\text { Leghorn }\end{array}$ & $\begin{array}{l}\text { WL- } \\
\text { GM }\end{array}$ & $\begin{array}{l}71^{a} \\
18^{b}\left(\cdot 79^{c}\right)\end{array}$ & $\begin{array}{l}\text { one male } \\
\text { / wwo female }\end{array}$ & $\begin{array}{l}A 2, B 15, C 1 \\
D 4, H 2,134 \\
L 1, K 1\end{array}$ & $\begin{array}{l}H b-I^{A}, H b-I I^{A} \\
H b-I I I^{A}, C t^{B}, E s-I^{S} \\
E s-2^{A}, A k p^{S}, L a p^{A}\end{array}$ & $\begin{array}{l}\mathrm{OTC}^{\mathrm{S}} \\
\text { MHC }^{B-G, B-F}\end{array}$ & $\begin{array}{l}\text { High sensitivity to fowl pox } \\
\text { High resistance to Marek's }\end{array}$ \\
\hline \multirow[t]{6}{*}{ Fayoumi } & $\mathrm{PNP}$ & $\begin{array}{l}71^{a} \\
19^{b}\left(' 80^{c}\right)\end{array}$ & $\begin{array}{l}\text { two males } \\
\text { /one female }\end{array}$ & $\begin{array}{l}A 2, B 1, E 1 \\
C 3, D 5, H 2 \\
I 5, I 2, P 2\end{array}$ & $\begin{array}{l}H b-I^{A}, H b-I I^{A} \\
H b-I I I^{A}, C t^{B}, E s-I^{s} \\
E s-2^{A}, A k p^{S}, L a p^{A}\end{array}$ & $\begin{array}{l}\text { OTC }^{L} \\
\text { MHC }^{B-G, B-F}\end{array}$ & $\begin{array}{l}\text { Good immune-response to } \\
\text { sheep red blood cell and } \\
\text { Brucellosis }\end{array}$ \\
\hline & $\begin{array}{l}\text { PNP } \\
/ \text { DO }\end{array}$ & $\begin{array}{l}90^{a} \\
8^{b}\left({ }^{\prime} 90^{c}\right)\end{array}$ & $\begin{array}{l}\text { five to six males } \\
\text { t two females }\end{array}$ & $\begin{array}{l}A 4, B 1, E 1 \\
C 3, D 5, H 2 \\
I 5, I 2, P 2\end{array}$ & $\begin{array}{l}H b-I^{A}, H b-I I^{A} \\
H b-I I^{A}, C t^{B}, E s-I^{S} \\
E s-2^{A}, A k p^{S}, L a p^{A}\end{array}$ & $\begin{array}{l}\mathrm{OTC}^{\mathrm{L}} \\
\mathrm{MHC}^{B-G, B-F}\end{array}$ & Double Oviducts \\
\hline & PNN & 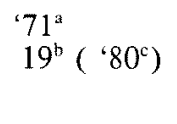 & $\begin{array}{l}\text { two males } \\
\text { /two females } \\
\text { from PNP }\end{array}$ & $\begin{array}{l}A 4, B 1, E 1 \\
C 3, D 5, H 2 \\
15, I 2, P 2\end{array}$ & $\begin{array}{l}H b-I^{A}, H b-I I^{A} \\
H b-I I I^{A}, C t^{B}, E s-I^{S} \\
E s-2^{A}, A k p^{S}, L a p^{A}\end{array}$ & $\begin{array}{l}\mathrm{OTC}^{\mathrm{L}} \\
\mathrm{MHC}^{B \cdot G \cdot B-F}\end{array}$ & $\begin{array}{l}\text { Good immune-response to } \\
\text { sheep red blood cell and } \\
\text { Brucellosis }\end{array}$ \\
\hline & $\underset{/ 1}{\text { GSN }}$ & $\begin{array}{l}71^{a} \\
18^{b}\left(80^{c}\right)\end{array}$ & $\begin{array}{l}\text { one male } \\
\text { /two females }\end{array}$ & $\begin{array}{l}A 4, B 21 \\
C 3, D 4 \\
H 2, I 5 \\
L 2, P 2\end{array}$ & $\begin{array}{l}H b-I^{A}, H b-I I^{A} \\
H b-I I I^{A}, C t^{B}, E s-I^{S} \\
E s-2^{A}, A k p^{S}, L a p^{A}\end{array}$ & $\begin{array}{l}\mathrm{OTC}^{\mathrm{L}} \\
\mathrm{MHC}^{B-G, B-F}\end{array}$ & $\begin{array}{l}\text { Good immune response to sheep } \\
\text { red blood cell and Brucellosis } \\
\text { High sensitivity to fowl pox } \\
\text { High resistance to Marek's }\end{array}$ \\
\hline & $\underset{12}{\mathrm{GSN}}$ & $\begin{array}{l}71^{\mathrm{a}} \\
18^{\mathrm{b}}\left({ }^{\circ} 81^{c}\right)\end{array}$ & $\begin{array}{l}\text { three males } \\
\text { two females }\end{array}$ & $\begin{array}{l}A 4, B 21, C 3 \\
D 4, H 2, I 35 \\
L I\end{array}$ & $\begin{array}{l}H b-I^{A}, H b-I I^{A} \\
H b-I I I^{A}, C t^{B}, E s-I^{S} \\
E s-2^{A}, A k p^{S}, L a p^{A}\end{array}$ & $\begin{array}{l}\mathrm{OTC}^{\mathrm{L}} \\
\mathrm{MHC}^{B-G_{s} B-F}\end{array}$ & $\begin{array}{l}\text { Good immune response to } \\
\text { sheep red blood cell and } \\
\text { Brucellosis }\end{array}$ \\
\hline & GSP & $\begin{array}{l}71^{\mathrm{a}} \\
18^{\mathrm{b}}\left(\cdot 81^{\mathrm{c}}\right)\end{array}$ & $\begin{array}{l}\text { two males } \\
\text { /one female }\end{array}$ & $\begin{array}{l}A 4, B 21, C 3 \\
D 4, E 1, H 2 \\
L 1, K, P 2\end{array}$ & $\begin{array}{l}H b-I^{A}, H b-I I^{A} \\
H b-I I I^{A}, C t^{B}, E s-I^{S} \\
E s-2^{A}, A k p^{S}, L a p^{A}\end{array}$ & $\begin{array}{l}\mathrm{OTC}^{\mathrm{L}} \\
\mathrm{MHC}^{B-G, B-F}\end{array}$ & $\begin{array}{l}\text { Good immune response to } \\
\text { sheep red blood cell, Brucellosis, } \\
\text { ILT virus and Mycoplasma } \\
\text { Gallisepticum }\end{array}$ \\
\hline
\end{tabular}

${ }^{*} ;{ }^{\text {a) }}$ starting year of lines, ${ }^{\text {b) }}$ generations after closed, ${ }^{\circ /}$ starting year of closed.

**; OTC $C^{L}$ and $\mathrm{OTC}^{S}$ indicate long $\left(^{L}\right)$ or short $\left(^{S}\right)$ type of intron 3 of OTC (ornithine transcarbamylase) gene, respectively.

$\mathrm{MHC}^{B-G, B-F}$ means that RFLP type fixed at $B-G$ and $B-F$ subregion of MHC B region.

to constructing resource families for genomic mapping in chicken, we have analyzed genetic variation within lines and genetic relationships between lines using the AFLP method.

\section{Material and Methods}

\section{Chicken}

As shown in Table 1, eight chicken lines of Black Minorca (BM-C), White Leghorn (WL-GM) and Fayoumi (PNP, PNP/DO, PNN, GSN/1, GSN/2, and GSP) were used in this study. These chicken lines have been maintained for more than 20 years, with few breeding stocks at NIBS. In all but one line, breeding started about 1970 and these lines have been maintained as closed colonies since as early as
1976. In most case there have been more than 20 generations until now. The details of these chicken lines are described Table 1 and elsewhere ${ }^{11)}$. These lines were fixed as homozygous to blood groups, blood protein types, several serum isozyme types and other loci including MHC. They are also fixed for immune response to plant lectins, e.g., PSA (Pisum sativum), peanut, sesame, tulip, STA (Solanum tuberosum), poke-weed aggulutinin, MPA (Maculura pomifera), ATA (Allium tuberosum) and VAA (Viscum albu$\min )$. The unique characteristics were fixed in a specific line as followings ; gs antigen in GSP line, chf positive activity in BM-C, PNP and GSP lines, chf negative in WL-GM, GSN/1 and GSN/2 lines, resistant to subgroup $\mathrm{A}$ and $\mathrm{E}$ and susceptible to $\mathrm{B}, \mathrm{C}$ and 
AFLP analysis of different chicken lines

$\mathrm{D}$ leukosis viruses in BM-C lines. The BM-C, WL-GM and GSN/1 lines were resistant to Marek's disease, but susceptible to the fowl pox. Fayoumi lines except GSN/1 were good immune responders against sheep red blood cell or Brucellosis. Also, BM-C line was a low responder to Mycoplasma gallisepticum, while GSP line was a high. PNP/DO line has a characteristic of double oviducts. RFLP types of the B-G or B-F in the subregion of MHC B were fixed and the size of intron 3 (either long or short) of ornithine transcarbamylase gene are also fixed in all lines.

Ten males from each line were used for AFLP analysis to exclude the effect of chromosome $W$ on the AFLP pattern, as males are homozygous for the chromosome $\mathrm{Z}$

\section{AFLP analysis}

The procedures of AFLP were performed essentially as described by Vos et al. ${ }^{12)}$ with minor modification. Genomic DNA (500 ng) was digested for $1 \mathrm{~h}$ at $37^{\circ} \mathrm{C}$ with 5 units of restriction enzyme, Mse I (NEW ENGLAND BioLabs) and EcoR I (Bochringer Mannheim), in final volume of $40 \mu l$ containing 50 $\mathrm{mM}$ Tris- $\mathrm{HCl}$ ( $\mathrm{pH} \mathrm{7.4),} 1 \mathrm{mM}$ EDTA, $10 \mathrm{mM} \mathrm{MgCl}_{2}$, $1 \mathrm{mM}$ DDT (pH 7.9) and $20 \mathrm{ng} / \mu \mathrm{l}$ BSA. To ligate the restricted DNA fragments and adapters, a $10 \mu l$ of ligation solution containing $1 \mathrm{mM}$ ATP, $5 \mathrm{pmol}$ EcoR I adapter ( $5^{\prime}$-CTCGTAGACTGCGTACC $/ 5^{\prime}$ AATTGGTACGCAGTCTAC), $50 \mathrm{pmol} M \mathrm{Mse}$ I adapter ( $5^{\prime}$-GACGATGAGTCCTGAG/5' -TACTCAGGACTCAT) and 1 unit of T4 DNA ligase (Phamarcha) was mixed and incubated for $3 \mathrm{~h}$ at $37^{\circ} \mathrm{C}$. The ligated DNA fragment solution was then diluted to $1 / 10$ with $10 \mathrm{mM}$ Tris- $\mathrm{HCl}, 0.1 \mathrm{mM}$ EDTA $(\mathrm{pH} 8.0)$ and then stored at $-20^{\circ} \mathrm{C}$. The primer sequences employed for the first selective amplification are as follows; EcoR I-A (5' -GACTGCGTACCAATTCA) and $M s e$ I-C ( $5^{\prime}$-GATGAGTCCTGAGTAAC), and those for the second amplifications are EcoR I-A-AC and Mse I-C-AC, -AG, -GT, -GA. The PCR conditions employed were as described by Vos et al. ${ }^{12)}$. The PCR products were mixed with a half volume of stop solution containing 95\% formamide, $10 \mathrm{mM}$ EDTA, 0.1\% Basic Fucsin and $0.01 \%$ Bromophenol blue $(\mathrm{pH} \mathrm{9.0)}$, and were analyzed with $1 \times$ TBE buffer on an automated DNA sequencer (LONG READER 4200, LI-COR) using $4 \%$ polyacrylamide gel containing $6.3 \mathrm{M}$ Urea.

\section{Data analysis}

Polymorphic bands; we defined the uncommon band observed through all individuals as polymorphic bands.

Band sharing (BS); polymorphic bands were scored using a binary system of 1 or 0 for the presence or absence of a band in each individual. The BS is the ratio that the frequency of the same polymorphic bands being observed between two individuals. The average of BS is the sum of all polymorphic bands and is expressed by the following equation ${ }^{5)}$ :

$$
\mathrm{BS}=2 \mathrm{Nab} /(\mathrm{Na}+\mathrm{Nb})
$$

where $\mathrm{Nab}$ is the number of commonly shared polymorphic bands between individual $\mathrm{a}$ and $\mathrm{b}$. $\mathrm{Na}$ and $\mathrm{Nb}$ are the total numbers of polymorphic bands in individuals $a$ and $b$, respectively.

Genetic distance (D) ; GD is expressed by the following equation :

$$
\mathrm{D}=1-\mathrm{BS}
$$

A dendrogram using genetic distances was constructed with the unweighted pair group methods average (UPGMA) using the MEGA package program $^{8}$.

\section{Results and Discussion}

\section{The frequency of the polymorphic bands}

In this study, the four selective primer sets were used to detect AFLP bands of ten males in each line. The size of the AFLP bands detected ranged from 100 bp to $600 \mathrm{bp}$. Figure 1 shows representative AFLP bands from $320 \mathrm{bp}$ to $580 \mathrm{bp}$ of four chicken lines. We selected high intensity bands for scoring and by the four primer combination sets 188 bands were scored through eight chicken lines, in which 106 $(56 \%)$ were common through all chickens, and the remaining $82(44 \%)$ were polymorphic. In the figure, polymorphic bands are shown by arrows. The number of polymorphic bands between breeds was high, while low in a breed and the minimum frequency within a line. Numbers of polymorphic band within lines ranged from 5 to 15 ; the maximum value, 15 bands, was observed in WL-GM line, while the mini- 


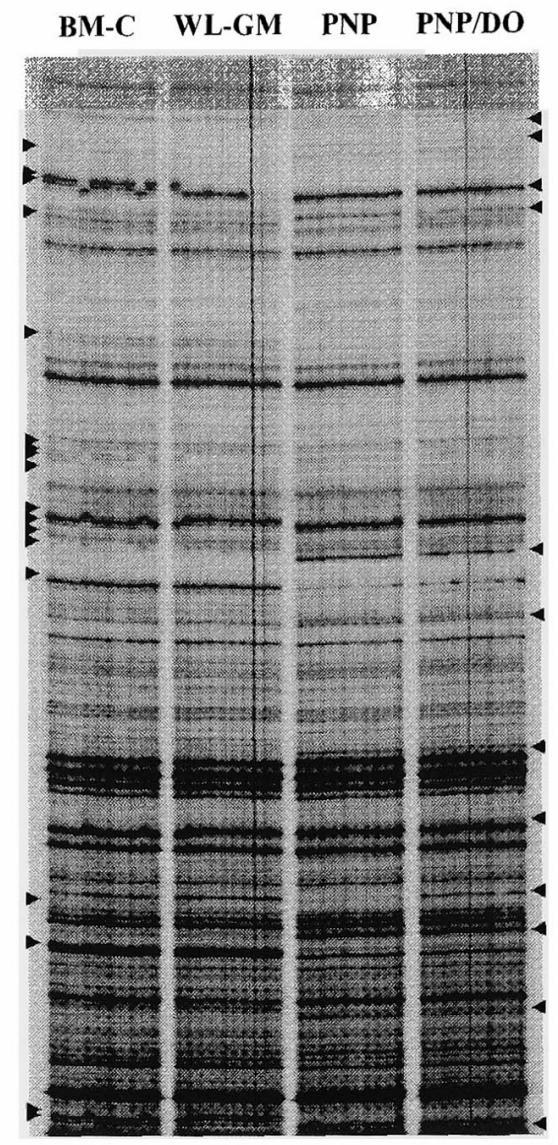

Fig. 1. AFLP pattern of 4 chicken lines.

BM-C : Black Minorca C line, WL-GM : White Leghorn GM line, PNP and PNP/DO : Fayoumi lines. AFLP : Amplified fragment length polymorphism. Arrows show polymorphic bands.

mum, 5 bands, in the PNP line.

Initially, Vos et al. ${ }^{12)}$ employed two restriction enzymes Eco R I and Mse I, and the combination was preferably used in plant genome analysis ${ }^{4)}$. Since then, many combinations were tested in different species to get more polymorphic information. These combinations are Pst $\mathrm{I} /$ Mse I in rice $^{14)}, E c o \mathrm{R} \mathrm{I} / \mathrm{Mse} \mathrm{I}$ in lentil (Lens sp.) $)^{2)}, E c o \mathrm{R} \mathrm{I/Taq} \mathrm{I} \mathrm{in} \mathrm{cattle}{ }^{1,9)}$ and chicken $^{3)}, E c o \mathrm{R} \mathrm{I} / H$ in $\mathrm{PI}$ and $E c o \mathrm{R} \mathrm{I} / M s p$ I in chicken $^{6)}$ and Sse $\mathrm{I} / \mathrm{Mse} \mathrm{I}$ in rat ${ }^{10)}$. Until now however, no case using EcoR I/Mse I is reported in mammalian and avian species, so here we applied the combination and successfully introduced the combina- tion as shown in the results.

Comparison of BS values between and within chicken lines

Table 2 shows genetic distance matrix and average band sharing (BS) values between eight chicken lines. Average BS values estimated within a line are shown in the center diagonal, in which the values range from 0.91 to 0.97 . BS values of within lines were 0.92 in BM-C and 0.91 in WL-GM, while 0.95-0.97 in Fayoumi lines. This suggests that more genes were fixed in Fayoumi lines than lines of the other breeds. The average BS values of inbred lines estimated from microsatellite loci ${ }^{13)}$ or from DNA fingerprinting ${ }^{73}$ are almost 1.00 , so that the eight lines employed here are not inbred lines. As shown in the Table 2, the lowest BS value between lines was 0.37 , so that the level of crossbred would be expected to be around this value. Therefore, it is suggested that the extent of inbreeding of these lines is considerably intensified. Average BS values between lines are shown in the below diagonal, the values between BM-C and Fayoumi lines were 0.48 to 0.51 , those between WL-GM and Fayoumi lines were 0.37 to 0.49 , and that between BM-C and WL-GM line was 0.50 . The values between 6 Fayoumi lines were high : they ranged from 0.73 and 0.88. It is obvious that the values between Fayoumi lines are higher than those obtained between breeds.

Until now, many studies have been conducted on genetic distances and genetic relationships assessed by DNA polymorphism using different methods, i.e., DNA fingerprinting, microsatellite analysis, RFLP and RAPD. Those are powerful, but with several disadvantages. DNA fingerprinting and RFLP require large quantities high quality DNA. To overcome to these disadvantages, analysis of microsatellite loci are sometimes performed, but primer combinations numbering in the hundreds are required. However, the AFLP method described here, is convenient and needs less than $1 / 10$ volume the purified DNA required by the original DNA fingerprinting method. Thus, this method will be the most useful for DNA fingerprinting in assessment of genetic structure of animal populations and genetic relationships between animal groups.

Genetic distances among eight chicken lines 
AFLP analysis of different chicken lines

Table 2. Genetic distance matrix (above diagonal) and average BS value (below diagonal) between eight chicken lines and BS value (center diagonal) within eight chicken lines from AFLP polymorphic bands

\begin{tabular}{|c|c|c|c|c|c|c|c|c|}
\hline & \multicolumn{8}{|c|}{ Lines $^{1)}$} \\
\hline & BM-C & WL-GM & PNP & PNP/DO & PNN & GSN/1 & $\mathrm{GSN} / 2$ & GSP \\
\hline $\mathrm{BM}-\mathrm{C}$ & 0.92 & 0.50 & 0.52 & 0.52 & 0.51 & 0.52 & 0.49 & 0.50 \\
\hline WL-GM & $0.50^{\circ}$ & 0. & 0.63 & 0.58 & 0.63 & 0.53 & 0.51 & 0.55 \\
\hline PNP & 0.48 & 0.37 & 0.95 & 0.12 & 0.12 & 0.25 & 0.21 & 0.20 \\
\hline $\mathrm{PNP} / \mathrm{DO}$ & 0.48 & 0.42 & 0.88 & 0.96 & 0.1 & 0.27 & 0.21 & 0.24 \\
\hline PNN & 0.49 & 0.37 & 0.88 & 0.85 & & 0. & 0.23 & 0.25 \\
\hline GSN/1 & 0.48 & 0.47 & 0.75 & 0.73 & 0.76 & & 0.19 & 0.19 \\
\hline $\mathrm{GSN} / 2$ & 0.51 & 0.49 & 0.79 & 0.79 & 0.77 & 0.8 & & 0.23 \\
\hline GSP & 0.50 & 0.45 & 0.80 & 0.76 & 0.75 & 0.81 & 0.77 & \\
\hline
\end{tabular}

${ }^{1)}$ BM-C and WL-GM represent lines of Black Minorca and White Leghorn, PNP, PNP/DO, PNN, GSN/1, GSN/2 and GSP represent Fayoumi lines.

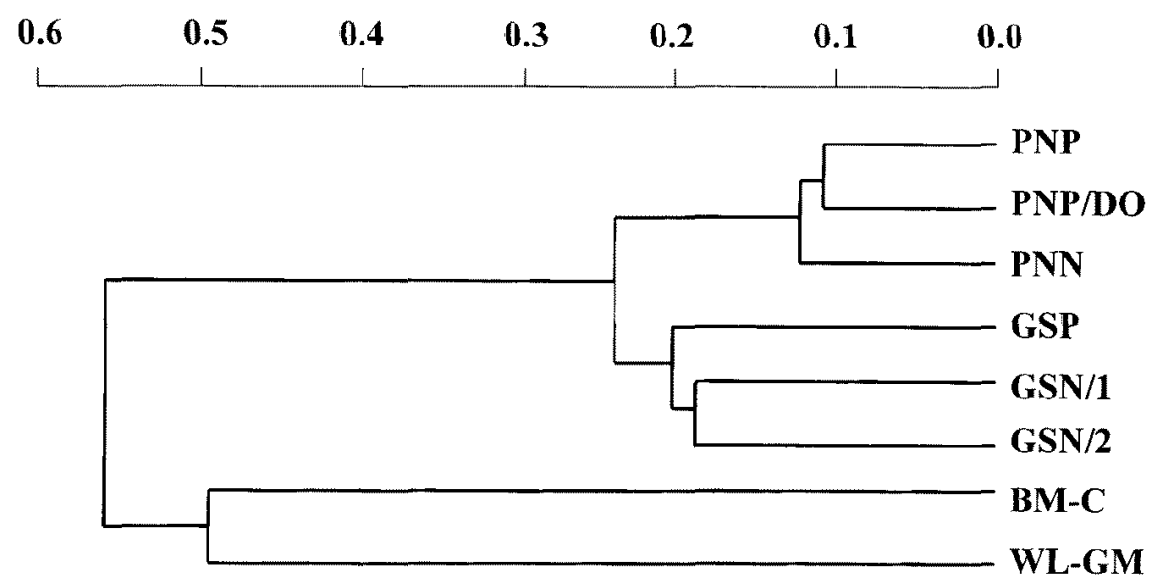

Fig. 2. Genetic relationships between 8 chicken lines being drawn by UPGMA depending on genetic distance.

BM-C : Black Minorca C line, WL-GM : White Leghorn GM line, PNP, PNP/DO, PNN, GSN/1, GSN/2 and GSP are Fayoumi lines. UPGMA : Unweighted pair group methods average.

Genetic distances among eight chicken lines are given in Table 2. The values among PNP, PNP/DO and PNN were the smallest, ranging from 0.12 to 0.15 . On the other hand, WL-GM showed the greatest distant values either with these PN lines or GS lines. The value between BM-C and WL-GM were 0.50.

Figure 2 shows the dendrogram drawn by UPGMA based on the genetic distances. By AFLP analysis 


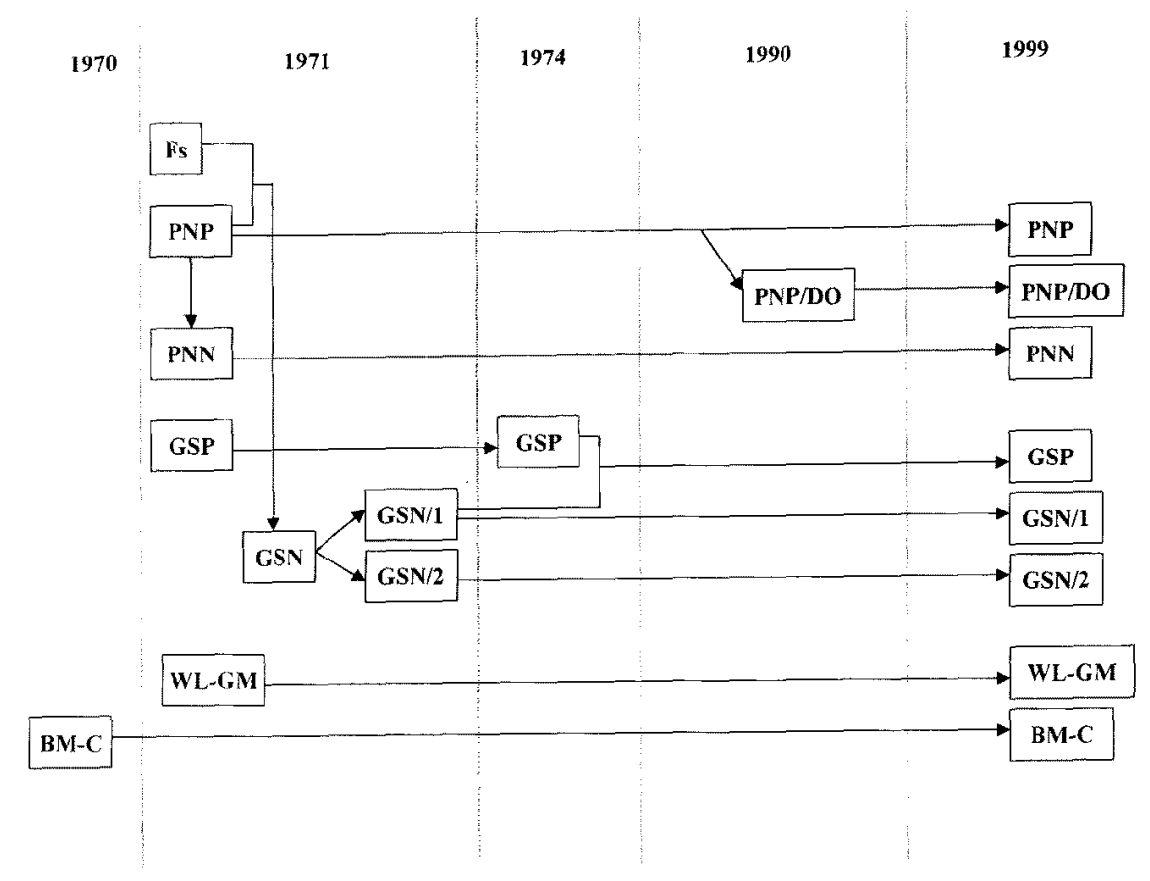

Fig. 3. The background of the construction of 8 chicken lines.

BM-C : Black Minorca C line, WL-GM : White Leghorn GM line, Fs, PNP, PNP/DO, PNN, GSN/1, GSN/2 and GSP are Fayoumi lines.

using 4 primer combinations, eight chicken lines are clearly classified into three breed dependent groups, i.e., WL, BM and Fayoumi. In the Fayoumi lines, it was classified into two groups, PN lines and GS lines, depending on the breeding history of each line. As shown in Fig. 3, both lines, PNP/DO and PNN, were derived from PNP which was established in 1971 and all are maintained as closed colony. GSN line was established in 1971 by crossing of two independent Fayoumi lines, PNP and Fs. And since then, GSN/ 1 and GSN/2 have been maintained. The GSN/1 was established as a group being negative for leukosis gs antigen, while the GSN/2 line has the same characteristics as the GSN/1, but is the congenic line introducing muscular dystrophy characteristic. The GSP was established at 1971 and then crossed with GSN/1 at 1974 , and since then it has been maintained as a closed colony. Therefore, within all Fayoumi lines PNP/DO, PNN and PNP have the same origin, while GSN $/ 1, G S N / 2$ and GSP represent a breeding group. From these results, the AFLP banding pattern appears to accurately reflect the breeding history of these chicken lines.

\section{Comparison of line specific bands between lines}

For the purpose of this discussions, we will define a "line-specific band", as a band which is observed in all individuals in a line, but is not observed in any individual of another line. Table 3 shows the line-specific bands. If one imagines a backcross family between WL-GM and Fayoumi PNP lines, there would be many different genetic characteristics e.g., blood groups of B1, B15, C1, C3, D4, D5, E1, I2, I5, I34, $\mathrm{P} 2, \mathrm{~L} 1$ and $\mathrm{K} 1$ and OTC genotypes of long or short intron 3 etc. (Table 1). These different characteristics are fixed in each line. WL-GM line has 28 linespecific bands against PNP line, while the reverse was 21. In the AFLP analysis, distinguishing heterozygous bands from homozygous bands was difficult, so a backcross family is better for linkage analysis than a F2 family. Backcrossing a male is more easier than the reverse in chickens, so WL-GM would preferably be used as a male. In that case, one could imagine as 
AFLP analysis of different chicken lines

Table 3. The number of line-specific AFLP bands when compared two chicken lines

\begin{tabular}{lllllllll}
\hline \hline & \multicolumn{7}{c}{ Lines $^{1)}$} \\
\cline { 2 - 9 } & BM-C & WL-GM & PNP & PNP/DO & PNN & GSN/1 & GSN/2 & GSP \\
\hline BM-C & & & & & & & & \\
WL-GM & $16 / 18^{2)}$ & & & & & & \\
PNP & $19 / 18$ & $28 / 21$ & & & & & \\
PNP/DO & $21 / 18$ & $28 / 19$ & $3 / 3$ & & & & \\
PNN & $19 / 18$ & $28 / 20$ & $3 / 3$ & $6 / 4$ & & & \\
GSN/1 & $20 / 20$ & $25 / 20$ & $9 / 11$ & $7 / 10$ & $5 / 10$ & & \\
GSN/2 & $20 / 21$ & $22 / 17$ & $5 / 10$ & $5 / 12$ & $3 / 12$ & $5 / 8$ & \\
GSP & $17 / 24$ & $26 / 15$ & $5 / 9$ & $6 / 13$ & $6 / 13$ & $6 / 10$ & $7 / 11$ & \\
\hline
\end{tabular}

${ }^{1}$ BM-C and WL-GM represent lines of Black Minorca and White Leghorn, PNP, PNP/DO, PNN, GSN $/ 1$, GSN $/ 2$ and GSP represent Fayoumi lines.

2) The line-specific band between two lines was characterized as commonly observed band in one line and no corresponding band in other line. The number of left side represents the line-specific bands of chicken lines in vertical column and that of right side corresponds chicken lines expressed in horizontal lines.

shown here, that one could expect 28 line specific bands using four primer sets. By simple calculation, one will get 780 polymorphic WL-GM line-specific bands using about 110 primer sets. The 780 bands distribute 20 markers on average, on each chromosome and average intervals between markers are about $5 \mathrm{cM}$ and this distance is good enough to map a candidate gene as an initial step in positional cloning. As shown here, observation of line-specific bands assessed by preliminary AFLP analysis gave us important information for construction of resource families for mapping. Recently, Knorr et al. ${ }^{6)}$ reported 377 AFLP polymorphic bands using 36 primer combination sets in the East Lansing reference family, while Herbergs et al. ${ }^{3)}$ got 475 AFLP bands using 57 primer sets in the Wageningen resource family. The average polymorphic bands per primer set was 10 in the East lansing family and 8 in the Wageningnen family. The difference of polymorhpic band number would reflect the source of the family, because the former was constructed with WL and Jungle fowl and the latter was between two broiler breeds. Therefore, the genetic distances between WL and jungle fowl is great when compared with that between broiler breeders, so the polymorphic band number would be more in the former than in the latter. Here, we got an average of
6 polymorphic bands per one primer set between WL and Fayoumi lines.

It is unclear at this time these differences truly reflect genetic distances between chicken lines or the specific combination of restriction enzymes employed. Therefore, prior to constructing a resource family for linkage analysis of a specific genetic characteristic, it is important to assess the genetic distances between lines that are going to be analyzed using AFLP fingerprinting. Further, the frequency of polymorphic bands need to be checked using the specific combination of restriction enzymes.

\section{Acknowledgements}

The authors acknowledge Dr. G. S. Harper (CSIRO Tropical Agriculture, Brisbane, Australia) for the preparation and suggestions of this manuscript.

\section{References}

1) Ajmone MP, Valentini A, Cassandro M, VecchiottiAntaldi G, Kuiper M. AFLP ${ }^{\mathrm{TM}}$ markers for DNA fingerprinting in cattle. Animal Genetics, $28: 418-$ 426. 1997.

2) Eujayl I, Baum M, Powell W, Erskine, Pehu M. A genetic linkage map of lentil (Lens sp.) based on 


\section{LEE, MANNEN, MIZUTANI and TSUJI}

RAPD and AFLP markers using recombinant inbred lines. Theoretical and Applied Genetics, $97: 83-89$. 1998.

3) Herbergs J, Siwek M, Crooijmans RPMA, Van der Poel JJ, Groenen MAM. Multicolour fluorescent detection and mapping AFLP markers in the chicken (Gallus domesticus). Animal Genetics, 30 : 274-285. 1999.

4) Hill M, Witsenboer H, Zabeau M, Vos P, Kesseli R, Michelmore R. PCR-based fingerprinting using AFLPs as a tool for studying genetic relationships in Lactuca spp. Theoretical and Applied Genetics, 93 : 1202-1210. 1996.

5) Jeffreys AJ, Morton DB. DNA fingerprints of dogs and cats. Animal Genetics, 18 : 1-15. 1987.

6) Knorr C, Cheng HH, Dodgson JB. Application of AFLP markers to genome mapping in poultry. Animal Genetics, $30: 28-35.1999$.

7) Kuhnlein U, Zadworny D, Dawe Y, Fairfull RW. Assessment of inbreeding by DNA fingerprinting : development of a calibration curve using defined strains of chickens. Genetics, $125:$ 161-165. 1990.

8) Kumar SK, Tamura K, Nei M. MEGA : Molecular evolutionary genetics analysis (Ver, 1.01). Pennsylvania State University. University Park, PA. 1993.
9) Nijiman IJ, Bradley DG, Hanotte O, Otsen M, Lenstra JA. Satellite DNA polymorphisms and AFLP correlate with Bos indicus-taurus hybridization. Animal Genetics, 30 : 265-273. 1999.

10) Otsen M, Den Bieman, Kuiper M, Pravenec M, Kren V, Kurtz TW, Jacob HJ, Lankhorst AE, Van Zutphen BFM. Use of AFLP markers for gene mapping and QTL detection in the rat. Genomics, 37 : 289-294. 1996.

11) Somes RG. International registry of poultry genetic stocks. 2-4. University of Connecticut Press. Storrs. 1988.

12) Vos $P$, Hogers $R$, Bleeker M, Reijans $M$, van de Lee T, Hornes M, Frijters A, Pot J, Peleman J, Kuiper M, Zabeau M. AFLP : a new technique for DNA fingerprinting. Nucleic Acids Research, $23: 4407^{-}$ 4414. 1995.

13) Zhou H, Lamont SJ. Genetic characterization of biodiversity in highly inbred chicken lines by microsatellite markers. Animal Genetics, 30:256-264. 1999.

14) Zhu J, Gale MD, Quarrie S, Jackson MT, Bryan GJ. AFLP markers for the study of rice biodiversity. Theoretical and Applied Genetics, 96 : 602-611. 1998. 